\title{
Gelungener Auftakt für die Fortbildungsreihe Muskuloskelettale Radiologie in Hamburg
}

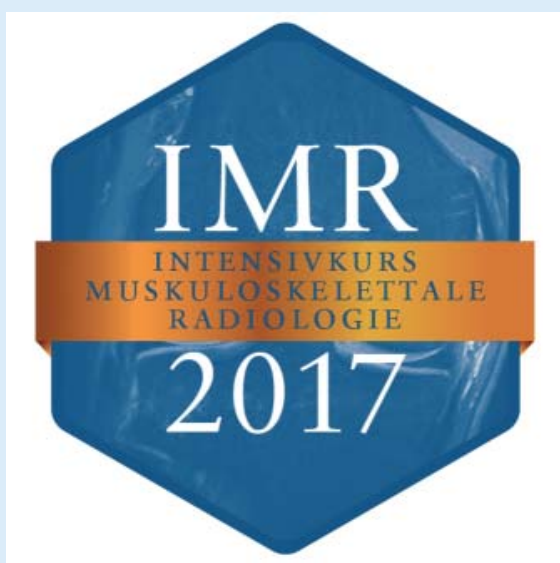

Erfolgreiche Premiere: Am 8. und 9. September 2017 fand in Hamburg zum ersten Mal der Intensivkurs Muskuloskelettale Radiologie (IMR) statt. Mit dieser zweitägigen Veranstaltung beginnt nun eine Fortbildungsreihe im Bereich Muskuloskelettale Radiologie. Angeregt wurde die Tagung durch den Vorstand der AG Bildgebende Verfahren des Bewegungsapparates. Die wissenschaftliche Leitung übernahm der Vorstandsvorsitzende PD Dr. Marc Regier vom UKE Hamburg-Eppendorf.

Spannende Themen und eine hochkarätige Referentenbesetzung lockten am zweiten Septemberwochenende 150 Teilnehmer in die Hansestadt Hamburg zum ersten Intensivkurs Muskuloskelettale Radiologie. Das Programm wurde als ausgewogene Mischung zwischen praxisrelevantem Basiswissen, Protokollempfehlungen für die tägliche Routine und innovativem Spezial-
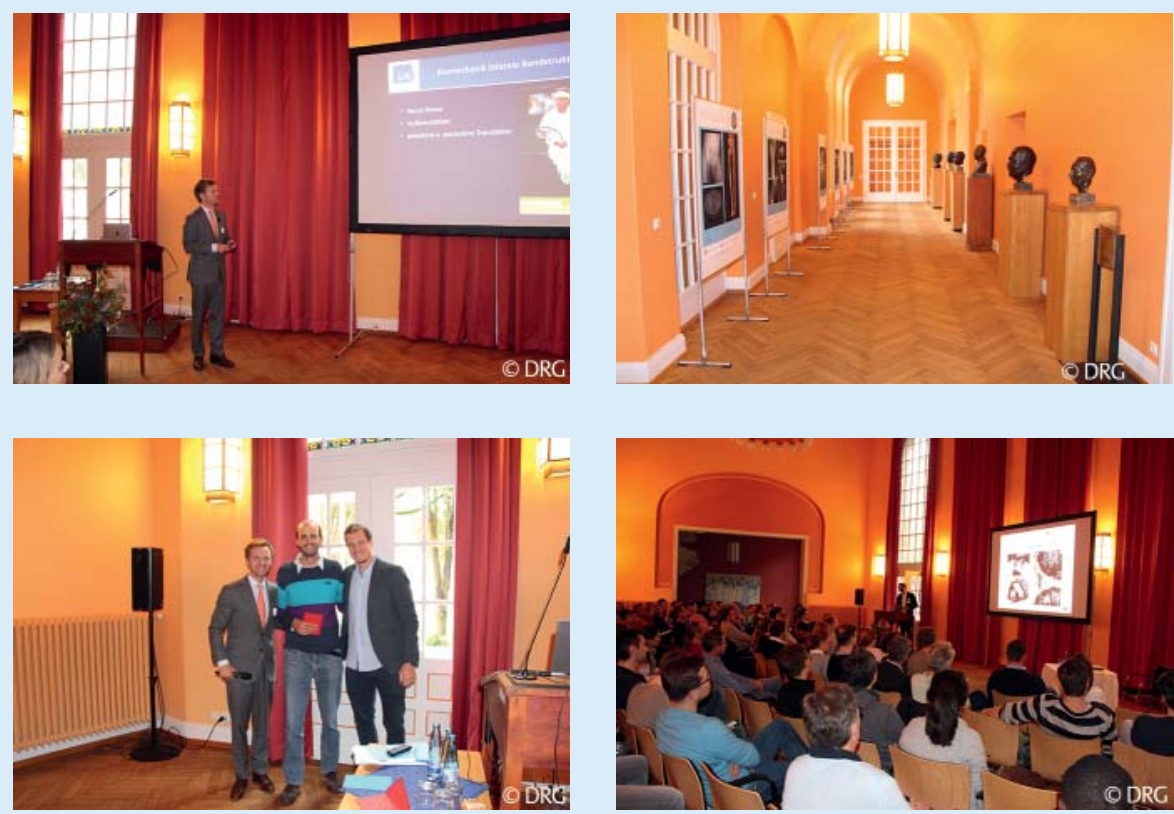

wissen konzipiert. Es wurden klinische Grundlagen, Schnittbildanatomie und Untersuchungstechniken erörtert, danach bildmorphologische Korrelate präsentiert sowie häufige und seltene Differenzialdiagnosen strukturiert vorgestellt. Im Rahmen der Zertifizierung der AG wird der Kurs als Spezialkurs angerechnet.

Auch der Spaß sollte nicht zu kurz kommen: In einem interaktiven Fallquiz konnten die Teilnehmer attraktive Preise gewinnen: eine Jahresmitgliedschaft in der Akademie Online der Deutschen Röntgengesellschaft für den Erstplatzierten sowie Bücher für die Zweit- und Drittplatzierten. Die Gewinner wurden in der sportlichen Highlight-Sit-

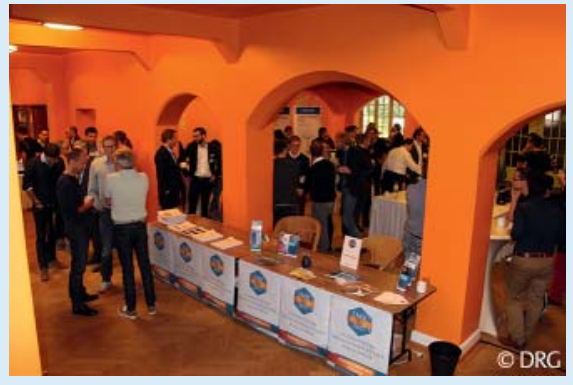

zung gezogen. Die Rolle der „Glücksfee“ übernahm der ehemalige HSV- und Nationalspieler Marcel Jansen, der sich im Anschluss für ein Meet-and-Greet zur Verfügung stellte. 